\title{
LA DIVISIÓN DE LAS TIERRAS MAPUCHE EN LA REDUCCIÓN GALLARDO TRANAMIL, 1979-1985
}

\author{
THE DIVISION OF MAPUCHE LANDS IN REDUCTION \\ GALLARDO TRANAMIL, 1979-1985 \\ Pedro Canales Tapia*
}

\begin{abstract}
En este trabajo se analiza y describe el contexto y la aplicación del decreto ley 2.568, que liquidaba las tierras mapuche, a partir de 1979, en el seno de una reducción mapuche de la provincia de Cautín, región de la Araucanía. La investigación presenta antecedentes de la vida en común de dicha reducción y sus habitantes; el cuadro político que rodeó a este proceso y los relatos de los y las mapuche afectados por la aplicación, rápida y arbitraria, de este cuerpo legal en tiempos de dictadura.

Palabras claves: Pueblo mapuche, división de tierras mapuche, decreto-ley 2.568, Memoria histórica.
\end{abstract}

This paper analyzes and describes the context and application of Decree Law 2,568, which liquidated the Mapuche lands, beginning in 1979, within a Mapuche reduction in the province of Cautin, in the Araucanía region. The investigation presents antecedents of the common life of said reduction and its inhabitants; the political picture that surrounded this process and the stories of the Mapuche affected by the rapid and arbitrary application of this legal body in times of dictatorship.

Key words: Mapuche people, division of Mapuche lands, decree law 2,568, Historical memory.

\section{Introducción}

El decreto-ley 2.568 entró en vigencia a fines de marzo de 1979, tras ceremonia de entrada en vigencia, llevada a cabo en Villarrica, y presidida por el dictador Augusto Pinochet (Canales, 2012a). Meses antes de su promulgación, Cristian Viven en Revista Mensaje, fue unos de los pocos que pudo opinar y criticar fuertemente esta iniciativa militar (Vives, 1979). Para este sociólogo, el decreto-ley fue un mal paso contra la integridad mapuche, pues amenazaba según sus palabras la pervivencia de este pueblo, además de ser un corpus asimilacionista en todo sentido (Vives, 1979).

Antes de este decreto-ley, la historia mapuche conoció de otros cuerpos legales durante el siglo XX. Los más conocidos son de 1930, 1931, 1945 y la ley indígena de Salvador Allende (Aylwin y Castillo, 1990; González, 1992; Correa et al., 2004). Los primeros, en general buscaron liquidar las reducciones establecidas y legitimadas por el propio Estado chileno entre 1883 y 1930, a partir de la entrega de Títulos de merced. El decreto-ley de Pinochet indicaba que su iniciativa venía a poner fin a este proceso histórico
(DA, 1979). La hijuelación o propiedad individual era el horizonte de estas letras. En Villarrica, el dictador describía los beneficios que acarrearían a la población mapuche, la implementación de este decreto (DA, 1979).

Respecto de este decreto-ley y su proyección histórica, dos son los aspectos que hasta el día de hoy golpean en la dinámica social, el debate y la política. Nos referimos, por un lado, al profundo sentido neoliberal que tuvo esta medida, y por otro lado, la articulación política mapuche de resistencia a esta legislación, a partir del nacimiento de Ad Mapu y su trabajo de información y rechazo a este marco legal que, según sus palabras, atacaba la centralidad mapuche, la tierra y su posesión histórica como pueblo (López, 1990; Correa et al., 2004; Mariman et al., 2006; Bengoa, 2012; Pairican, 2015). A partir de este hito, las forestales -en lógica neoliberal- ingresaron de manera sostenida, categórica y nociva a territorio histórico mapuche, tensionando aún más la situación en estas latitudes (Vergara, 1984; Guadichaud, 2015).

El presente trabajo centra su atención, así, en una reducción -llamadas en general, comunidades-, más puntualmente la reducción Gallardo

\footnotetext{
* Universidad de Santiago de Chile. Instituto de Estudios Avanzados. Santiago, Chile. Proyecto FI UVM 2016-2017.
} Universidad Viña del Mar. Correo electrónico: pedro.canales@usach.cl 
Tranamil, ubicada en el sector llamado Rulo, al suroeste de la ciudad de Nueva Imperial. El Título de Merced post ocupación militar chilena, le fue entregado al lonko Gallardo Tranamil el año 1900 (Canales, 1997). Desde ahí a la fecha varios capítulos de colonialismo chileno, a partir de leyes, programas estatales, la educación, entre otros, han marcado la historia mapuche en este sector. La diáspora o migración a las grandes ciudades, por ejemplo, es uno de los puntos más relevantes de esta diacronía (Ancan, 1994; Antileo, 2013a). También han sido relevantes en este caminar, las historias de despojo territorial (Correa et al., 2004; Correa y Mella, 2010; Canales, 2013), el racismo colonial (Canales, 1998) y el impacto en la vida cotidiana del peso de un estado asimilacionista y uniformador (Nahuelpan et al., 2012; Antileo et al., 2015).

Así, este trabajo se interna en los tejidos de memoria de hombres y mujeres mapuche que vivieron el proceso de división de sus territorios. Los relatos no son uniformes, ni lineales, ni menos absolutos; son la expresión de esta época; un tiempo en que la dictadura se dio a la tarea de reconfigurar el colonialismo chileno en su más amplio sentido, como bien lo expresa Sergio Caniuqueo en algunos de sus trabajos (2006, 2013). Desde una perspectiva teórica que dialoga con los debates referidos a colonialismo y descolonización en América Latina y Chile (Fanon, 1961; Rivera, 1984; Nahuelpan et al., 2012; González Casanova, 2017; Antileo, 2013b; Cabrera Llancaqueo, 2016; Canales 2016), esta proposición es una exclamación que pide mirar la historia mapuche en particular, e indígena en general con los ojos, zapatos y experiencia de vida, de sus protagonistas, tratados en la historia oficial y escolar como verdaderos antagonistas del "progreso" del pueblo chileno, como expresión de violencias coloniales estructurales presentes en este esquema social.

\section{Notas de historia política}

Avanzado el siglo XX las organizaciones Mapuche se extendieron y fueron asumiendo una inusitada figuración para un observador externo. A la Sociedad Caupolicán Defensora de la Araucanía (1910) y la Federación Araucana (1916), esta última liderada por Manuel Aburto Panguilef de Loncoche (Menard, 2013), se sumaron otras durante el siglo XX (Foerster y Montecino, 1988). A lo anterior se suman los diputados que representaron a la "raza mapuche" como indican los discursos de dicha época. En 1924 y 1973 fueron ocho/purra los Mapuche que tuvieron escaño, voz y voto en el Congreso chileno: Francisco Melivilu, Manuel Mankelef, Arturo Huenchullan, José Cayupi, Esteban Romero, Venancio Coñoepan, Manuel Rodríguez Huenuman y Rosendo Huenuman (Canales, 2012b: 108). El discurso púbico de estos Mapuche estuvo “(...) marcado por la evocación o rescate de la historia propia (...), a pesar de manifestar evidencias de asimilación cultural, cuando se refieren al patriotismo, a los araucanos y el aporte a Chile" (Canales, 2012b: 109). De Manuel Mankelef, además de los aspectos de su carrera política, podemos resaltar en estas líneas, ser el mapuche que inauguró lo que hoy llamamos letras mapuche, o el instante de creatividad política que, emergido y consolidado como un corpus discursivo cruzado por el debate de descolonización y la autonomía.

En la década de 1960 fue notoria la presencia de la Reforma Agraria en los latifundios chilenos y en territorio Mapuche. Martin Correa, Raúl Molina y Nancy Yáñez sostienen que “(...) la Reforma Agraria dio pie para que se desbordara la relación de las comunidades mapuches con el Estado, en cuanto a las reivindicaciones territoriales", lo que obligó al aparato oficial a "adaptarse y abarcar a los mapuches, reconocer la demanda de tierras, conocer y resolver los conflictos e incorporar a las familias y comunidades en el proceso de ampliación de tierras" (Correa et al., 2004: 11).

Según informe CIDA de 1966, sostienen Correa, Molina y Yáñez, la escases de tierra Mapuche en la Araucanía se debía al latifundio, a la "acción forzada" y al hecho de no poseer "recursos suficientes para aumentar la producción" (Correa et al., 2004: 108). También se establece la urgencia de proteger las tierras Mapuche de la usurpación e inyectar más recursos a las comunidades. Eduardo Frei Montalva derogó la ley de Jorge Alessandri e instauró la ley $\mathrm{N}^{\mathrm{o}} 16.640$, la cual, según los autores antes citados, no poseyó mayor injerencia Mapuche. Estos autores solo mencionan a

“(..) don Jorge Elgueta en representación del Movimiento Indígena de Cautín; don Carlos Huaquiñir, miembro 
de la Corporación Lautarista; don Juan Huichalaf, presidente del Movimiento Indígena de Cautín; y, don Alberto Melillan, de la Corporación Lautarina" (Correa et al., 2004: 105).

Así presentado el panorama, la Reforma ignoró a la así denominada "Cuestión Mapuche", relegándola a un asunto propio de la ley indígena vigente hacia 1966 (Correa et al., 2004: 105). Otro estudio, en este caso de Martín Correa y Eduardo Mella sostiene respecto de la Reforma Agraria y los Mapuche, que esta comenzó en Malleco antes de la entrada en vigencia la ley. La comunidad de Los Lolocos, sostienen estos autores, "comienzan a reivindicar tierras usurpadas que se encontraban dentro del fundo Chihuaihue" (Correa y Mella, 2010: 158). Con la entrada en vigencia de la nueva ley de Reforma Agraria en el Gobierno de la democracia cristiana, prosiguieron las movilizaciones y recuperaciones territoriales.

Emblemáticos fueron los hechos de 1967 en Lumaco en la recuperación de tierras al "ocupar el fundo Moena", y el surgimiento de la Corporación Lautaro de Lumaco Limitada, "instancia de organización y producción altamente exitosa" (Correa et al., 2004: 108). En 1969 nuevamente las comunidades de Lumaco volvían a ocupar masivamente -la prensa de la época habló de medio millar-, fundos como el Reñico y Pililmapu “(...) donde procedieron a levantar viviendas, a efectuar labores agrícolas y a pastorear sus animales" (Correa et al., 2004: 110). Las reducciones no aceptaron la erradicación; frente a esto, el Gobierno aplicó la ley de reforma agraria en territorio mapuche (Correa et al., 2004: 111-112).

En la última etapa del Gobierno de Frei Moltalva, la agudización de las movilizaciones y el accionar Mapuche se incrementó. La provincia de Cautín se tomaba la escena noticiosa y el accionar del Movimiento Campesino Revolucionario (MCR) marcó la pauta de ahí en más, con sus "corridas de cerco" y el bullado "Cautinazo" en pleno Gobierno de la Unidad Popular (Bastías, 2009). En la Sangre del copihue de Florencia Mallon, se describe con nitidez dicho proceso, centrando la mirada en la comunidad Nicolás Ailío. Sostiene la autora, que la madruga del 20 de diciembre de 1970, las comunidades de Ailío y Pichingual "con algunos socios de Nehuentúe y trabajadores del fundo cercano del mismo nombre" para reunirse cerca de Carahue y “(...) tomar el fundo Rucalán, propiedad de Juan Bautista Landerretche Mendoza y de su esposa, Violeta Maffei Herrera" (Mallon, 2004: 11).

En este proceso, la injerencia del MIR y de su brazo campesino MCR fue notorio y recordado por sus protagonistas. Investigación emblemática acerca de esta relación histórica es Memorias de la lucha campesina de Julián Bastias, publicada en 2009. En años recientes, investigadores jóvenes como Cristian Suazo Albornoz, Jaime Navarrete Vergara y Patricio Macaya Bermejo, han desarrollados tesis -en sus estudios de posgrado- relativas a esta historia y sus implicancias, registrando en todos los casos el compromiso de visibilizar en estas historias la figura Mapuche (Navarrete, 2018; Suazo, 2018). Iniciado el año 2019, Marie Urrutia Leiva, estudiante de historia de la Usach, también presentó un trabajo de tesis referido a este proceso, marcando énfasis en los Nütram/conversaciones vividos en la zona de Nehuentúe, comuna de Carahue, provincia de Cautín. El susurro de los Kuifikeche, gente que adquiere sabiduría a partir de la experiencia de los años, como sostiene la autora en su trabajo, hacen de esta propuesta un hito joven en trabajos de este tipo (Urrutia, 2019). Hace un tiempo, en este sentido, el municipio de Nueva Imperial editó, gracias al Fondo de Arte y Cultura un trabajo referido a los y las kimche/gente sabia de Rulo. Don Luis Huaiquimil, la señora Sabina Higuera y don Pedro Pilquil, entre otros, fueron presentados con sus reflexiones y enseñanzas de cara a las nuevas generaciones de Mapuche, que mantienen el "orgullo" de las raíces y la historia propia.

Ahora bien, volviendo al relato central de este trabajo, los militares llegaron violentamente al poder y tras un período de indefiniciones ideológicas, asumieron como motor de la economía nacional al neoliberalismo. Victor Mella sostiene acerca de esta coyuntura, que:

"El gobierno de los militares puso fin al proceso de la Reforma Agraria, lo que significó la pérdida de las tierras recuperadas, así como también que se persiguieron políticamente a quienes habían participado en el proceso. Esta persecución se expresó en ejecuciones, 
desapariciones, torturas y encarcelamiento para muchos dirigentes mapuche" (Mella, 2007; 67).

Por su parte, Augusto Samaniego y Carlos Ruiz, plantean que tras las Reformas Agrarias de Frei Montalva y Allende, no fue solucionado el "problema Mapuche". Con la irrupción de la dictadura de Pinochet, "Por medio de la "contrarreforma agraria" (...)" fueron devueltas "a los latifundistas casi el 90\% de la superficie expropiada" (Samaniego y Ruiz, 2007: 420; Mella, 2007). Según estos autores: "Solo unas 25.000 hectáreas fueron transferidas a mapuches mediante la parcelación efectuada (...)" tanto por la Corporación de Reforma Agraria como por "transferencia de tierras al Instituto de Desarrollo Agropecuario y la Dirección de Asuntos indígenas en la década de 1980" (Samaniego y Ruiz, 2007: 420).

Don Pedro Camilo, mapuche de la comunidad Gallardo Tranamil, comenta en torno a la noción de "lo común": “... en ese momento nosotros mayormente vivíamos más común, o sea, más comunidad, o sea, trabajábamos la tierra, no había tanta cerca, comúnmente se cuidaba los anímales, se trabajaba igual". Por su parte, Sabina Higuera Marín, involucra su recuerdo, injertando a propósito la visión pretérita de comunitarismo con el nivel en la calidad de vida poseída por los comuneros: "Antes yo, cuando era niña, fui chica, era común; uno llevaba su animal cualquier lado y había mucho más alimento, mucho más animales y esos animales nos ayudaban". El presidente de la comunidad en 1996, don Sergio Tranamil indica al respecto: "Mire! Por mi parte no lo encontré muy bueno yo; no muy bueno porque el gobierno sacrificó a los pequeños agricultores", no perjudicando según este dirigente a "los que tenían grandes extensiones de tierra (...), sino que a nosotros no más", sentenciando que "Como era la ley del gobierno teníamos que obedecer, así que yo creo que muchos no quedaron conforme".

De esta forma, el pueblo Mapuche fue drástica y sistemáticamente constreñido con la promulgación de leyes protectoras de indígenas durante el siglo XX y a lo largo de toda la vida republicana de Chile. Los habitantes de Gallardo Tranamil guardan el recuerdo político-moral que antecedió a la promulgación del señalado decreto-ley. Caracterizan la década de 1970. Involucran al gobierno de Salvador Allende en los márgenes que antecedieron la intervención militar, planteando la posterior dominación del miedo en el campo. La señora Graciela Pilquiñir describe sus imágenes y percepciones: "Allende malazo; esa vez había que andar limosna, comprando cuestiones, mercadería, harina cruda; de todo había que andar a la cola, las cinco de la mañana, a veces alojaba la gente pidiendo cosas... ese presidente fue muy malo..."

Si bien el comentario anterior es acotado al ámbito urbano; cuando la señora Graciela se refiere a la esfera rural, el enunciado es casi idéntico: "En el campo también estaba así. El que tenía politiquería, a esos le daban, esos acaparaban las cosas; el que tenía un poco de plata compraba y acumulaba cosas... No había politiquería en Rulo". Añadiendo:

"Después vinieron los militares... también anduvieron; esos que estaban politiquiando los tomaron preso, los apalearon... sí un vecino aquí lo tomaron preso allá abajo. Carabinero los trajo la señorita Zenobia (Quintremil) que vive allá arriba, tenía tierra ahí frente a los Gallardo, eso que compró José Pichun y ahí había siembra, la señorita trajo carabineros, vino arar la siembra; lo aró todo porque ella es una profesora, tiene plata ¿Pagaría?, no sé porque un pobre no lo va hacer asî".

La escasez aguda en una sociedad de subsistencia daña la actividad laboral de una comunidad, según sus protagonistas, además de ajar las características étnico-culturales de la población mapuche (Leiva, 1985; Oyarce, 1989). El gobierno de Salvador Allende, en la memoria mapuche, simbolizó esta Crisis. La dictadura militar, en el tejido némico de los habitantes de Gallardo Tranamil, inicio su camino de forma violenta y conflictiva. La tierra fue una vez más fuente de disputa, la fuerza pública, fue el elemento inhibidor preciso en favor de los intereses gubernamentales de mantener en silencio a los comuneros, y la riña entre mapuche el peor indicio de un futuro incierto. El relato popular de los Hijos de tierra no lo olvida.

José Gallardo Colifir, bisnieto del lonko Gallardo Tranamil, implicado directo en 
conflictos territoriales como el anterior, omitiendo el nombre del querellante, narra tal acontecimiento con aires de asombro y temor ante el atropello, evocando derechos ancestrales sobre su tierra y denunciando la prepotencia de Estado en aquellos años:

“Hay! cuando vino ese derrocamiento...
mandó dos camionada de carabine-
ro bien para matarme, yo no me opuse
nada y no tuve miedo tampoco. Entonces
araron el trigo, el trigo está así ya. Era
del Indap y al tiro di cuenta al Indap;
Indap dijo: "usted miró mal por eso que
lo araron' ¡Pero no eso! Esto es del caci-
que Gallardo Tranamil, como nosotros no
somos hijos, ya murieron, nosotros segui-
mos trabajando".

Los abusos y persecuciones, ampararon la formación de una tensa quietud en las comunidades mapuche. Auliel Millapi de la comunidad Cristóbal Relmul, en Rulo, sostiene que el temor tácito rondaba en cada rincón de los campos:

“... se veía... había un susto muy grande, una preocupación muy grande, o sea, había una preocupación muy grande de la gente. Me recuerdo mi viejo me decía 'no haga esto', 'no ande trayendo un fierro, ni armas ni cuchillos' porque 'te pueden llevar los milicos y te llevan y te apalean y te matan y simplemente te aporrean' por que llegaban en los campos, llegaban allá, todos armados".

La represión militar intentó amilanar los anhelos mapuches por recuperar sus territorios usurpados y mantener sus ritos y ceremonias ancestrales que contactan al pueblo, por medio de machis, con el mundo que la razón y el relato occidental no capta ni menos valora, a la hora de reflexionar en torno al devenir de la sociedad mapuche. El antropólogo Tom Dillehay, sostiene que el/la Machi cumple un rol fundamental al legitimar proyectos y planes de la comunidad y al mediar entre los suyos y la autoridad oficial. Para Dillehay, el/la Machi puede ejecutar estas funciones gracias a detentar el control del kimün/ conocimiento ancestral (Dillehay, 1995). Roberto Morales constató que:
"Muchas familias de campesinos mapuches continuaron siendo permanentemente hostigados por personal de carabineros de Chol Chol, Imperial y Almagro; los controlaban en las micros, los interrogaban donde los encontraran cerca de las actividades que estuvieron realizando, los amenazaban" (Morales, 1990: 15).

El recato frente a la autoridad y la vigilancia latente a la que se vieron expuestos, llevó a los comuneros de Rulo a reaccionar con inquietud y decisión el día que su bien mayor, la tierra, fue amenazada. Tal posición se explica al ser la tierra elemento esencial en el desarrollo integral de un grupo indígena que se llama así mismo gente de la tierra y en torno a la cual circulan los ciclos vitales de la naturaleza y la reproducción.

La señora Marcelina Pichun describe con claridad que la importancia del mapu radica en su utilidad crucial: “...para poder trabajar pues; -exclama la señora para poder tener su cosecha, para poder tener algo en la casa; para poder tener a los hijos; ahí se siembran y ahí se interesan por la tierra y así pasamos". Hugo Carrasco ha escrito acerca de lo que la señora Marcelina consigna, estableciendo el valor mítico de la tierra entre la población mapuche (Carrasco, 1992).

No es casualidad que la voz de una mujer aclare el valor concedido a la tierra por el pueblo mapuche. Ellas son las articuladoras de acciones y proyectos de pervivencia material y cultural. Sonia Montecino lo consigna de la siguiente forma: "Las mujeres mapuches modulan los sonidos de la historia" (Montecino, 1982: 22). Ellas regeneran su sociedad, educan a los hijos y dan orden y vigor a los espacios de socialización. La tierra no es un bien de lucro; es más, implica y reúne necesidades y sueños, solo ella da el alimento. Si a la señora Marcelina le consultan ¿es usted una mujer feliz?, la señora Marcelina responde: "Sí soy... paso bien, pero cuando no hay cosecha es triste, triste para poder encontrar la plata..."

La tierra es vital en este escenario. El decreto-ley 2.568 remeció la cotidianidad Mapuche. La comunidad como expresión moral, ancestral y/o espiritual que legitima el actuar de un pueblo, ordena las acciones sociales, y genera el espacio para el encuentro de lo vivo y lo muerto con la tradición, fue ignorada y sacudida por Ley. 
Los estereotipos dañinos y funcionales al poder, se desplegaron y primaron como en tantas otras veces. Milan Stuchlik, a propósito, define por estereotipo, aquellos “(...) constructos de sentido común que tienen el propósito de generar o justificar actitudes específicas de los chilenos hacia los mapuches" (Stuchlik, 1985: 165). Superada hace décadas la imagen del "guerrero valeroso" entre los chilenos, en tiempos de la aplicación del decreto-ley los constructos de sentido común chileno, marcadamente colonialista, signaron a los Mapuche de las comunidades como sujetos empobrecidos por las malas decisiones de Gobiernos anteriores, porque urgía sumarlos a la carrera del desarrollo y la productividad económica. Hoy en día, a partir de los discursos de los ministros del interior o subsecretarios, más la prensa, son catalogados de "Terroristas".

\section{La división de la división}

Entre 1883 y 1930 el antiguo territorio mapuche fue drásticamente dividido en tierras para colonos, tierras para ciudades y resabios para "los indios" (Bengoa, 2000; Mariman, 2006; Pinto, 2015). Entre 1930 y 1970 los Gobiernos chilenos se dieron a la tarea de dividir y poner fin a las tierras indígenas. Desde 1979 en más, asistimos a la división de la división de tierras restantes entre los mapuche. En la memoria de los y las habitantes de Gallardo Tranamil, se guarda el proceso de división de comunidades como una etapa difícil y confusa, en la cual el cerco y el título de dominio individual definieron una nueva cesura histórica en su caminar. Más ellos, no pidieron ni conocieron con anticipación-como indican los relatos- la estructura y alcances del decreto-ley 2.568. "La gente no pidió nada -recuerda Juan Mariqueo-, no pidió sino que el Gobierno puso esa ley porque después que hubo el golpe; de repente apareció esa ley que cada uno tenga su título y manda sus derecho...". La obligación fue evidente: “... fue algo que se vino aquí -sentencia Mercedes Coñay se hizo no más, o sea, para el que vivía acá, o sea, en todo caso...".

La noticia ingresó al reducto de forma abrupta; los comuneros se encontraron desinformados, sin orientación alguna respecto de la "nueva ley". Los militares desde una base de evidente subestimación, pretendieron dividir las comunidades con rapidez y sin dilación. No acogieron los planteamientos mapuche, ni fueron incluidos en la comisión correspondiente. El Diario Austral de Temuco (DA) confirma esta apreciación, al informar en su edición del 31 de marzo de 1979 que "reducciones mapuches de Victoria analizarán la nueva Ley Indígena" (DA, 1979). El efecto buscado por la prensa local intentó resaltar tal reunión como signo de libertad y amplitud de expresión. No obstante, tal noticia debió figurar en las series matutinas de uno o dos años antes cuando la Ley aún era proyecto y no tres días más tarde de su formal promulgación. "Impuso el Gobierno... sí impuso el Gobierno -puntualiza y concluye don Juan Pichun-; si eso de repente llegó, los dijeron, los empadronaron, contaron las personas: “¿Cuánto herederos hay? ¿Cuantos se han muerto? ... todas esas cosas y asî". Confirma dicha apreciación don Luis Huaiquimil: "La ley fue obligatorio, es general... no pidió nadie sino que de allá arriba vino... El presidente..."

Así como el pueblo mapuche no solicitó ni participó en la confección de tal Ley, tampoco fueron informados respecto de su promulgación. La incertidumbre cundió. La Ley fue conocida con absoluta posterioridad. Don Antonio Curimil, comenta al respecto: "Bueno... nadie estaba seguro si iba a ser así o no -recalca don Antonio, comunero fallecido en los últimos años-; eran comentarios, eso, nada más...". Su hija, Mercedes Curimil Ancamil, hoy presidenta de la comunidad, retroalimenta su mirada, complementando el argumento de su progenitor y sosteniendo premisas contundentes:

\begin{abstract}
"Uno no estaba seguro que iba a decir esa ley, no teníamos conocimiento más que nada; no se dio a conocer esa cosa y como iba a ser ley...". Recalcando: "Nadie dio a conocer, nadie de parte del Gobierno ni una cosa; se hizo como una cosa que la ley no se le dio a conocer; ya que estaba toda lista ahí ya se dio a conocer a la gente...".
\end{abstract}

Funcionarios del Instituto Nacional de Desarrollo Agropecuario, INDAP, y los medios radiales iniciaron la tardía labor. Todo estaba consumando desde Santiago warria. “... Si... se avisó... en la radio, vinieron a avisar también" sostuvo don Sergio Tranamil. El proceso de división se ejecutó en el Juzgado de Letras de 
Nueva Imperial archivándose como causa 873. El mentado proceso finalizó el 20 de diciembre de 1985. Dicho inicio se debía amparar en la petición voluntaria de división de al menos un comunero al abogado defensor de indígenas. En la comunidad Gallardo Tranamil no hay coincidencia en establecer las voces mapuches que solicitaron el inicio del proceso.

Ceferino López, puntualiza que la comunidad no había pedido a las autoridades la ley-división de sus tierras comunitarias, mas no desconoce la posibilidad que en otras comunidades de la región sus habitantes si lo hayan hecho: "No, nosotros no, no, no la habíamos pedido. No sé cómo salió esa ley, y así como salió una ley dijeron que en otra parte creo que pidieron y así que hubo mayoría”.

En cambio, Martín Huechuqueo recuerda que el proceso de división fue apoyado por algunos comuneros, y específicamente por él debido a su íntimo anhelo de obtener un título individual de propiedad, que asegurara su posesión de su tierra. Indica don Martín: “... No, no... voluntario; la tierra que uno cercó, sí voluntario". Todo indica, según el relato extendido, que la experiencia histórica de Huechuqueo como comunero, no le otorgó seguridad y bienestar, que la nueva situación, y según lo informado por funcionarios públicos, si le daría.

El abogado defensor de indígenas en aquella ocasión fue Carlos Koch Rivas, funcionario de INDAP. La cantidad de tierras a mensurar y dividir fue de 486,46 hectáreas. Los trabajos de campo se iniciaron en julio de 1981 siendo los topógrafos, Luis Núñez Le Bert, Jaime Ulloa Cerda y Máximo Sepúlveda.

En los comparendos $\mathrm{N}^{\circ}$ 586, 587 y 588 fueron planteados diez conflictos, posibles de paralizar la división. Protagonista en cuatro de los diez problemas, fue Zenobia Quintremi Quintre. Foerster y Montecino la citan como una de las primeras líderes mujeres Mapuche. En su Memoria de titulación como profesora, la maestra sostenía: "Desde mi infancia, cuando asistía a la escuela rural mixta en Almagro, a una legua de mi casa, empezó a germinar en mi mente la idea de estudiar para llegar a convertirme en una profesora”. Además de solicitar "(...) la destrucción de malos conceptos, de prejuicios inconcebibles en un país como el nuestro (...)" (Foerster y Montecino, 1988: 267-269).
Zenobia Quintremil reclamó por la alteración de goces entre su hermana Zoila y don Altao Coña; solicitó que la hijuela $\mathrm{N}^{\circ} 105$ asignada a su nombre quedase a nombre de José Pichun Catrileo, verdadero ocupante; declaró que su hijuela $\mathrm{N}^{\circ} 113$ fuese otorgada a Jhon Hope Paredes y señaló que la hijuela $\mathrm{N}^{\circ} 212$ a ella adjudicada debía ser traspasada a Francisco Muñoz Canobi, por ser este su ocupante hace 15 años, es decir, desde 1970 en adelante. Esto último, no obstante, difiere absolutamente con las declaraciones de Inés Muñoz Muñoz, cónyuge del potencial adjudicatario, quien señala haber llegado a la zona junto a su marido solo en 1984 .

Según consigna la sentencia de división del 20 de diciembre de 1985, en su agregado de propiedad. Tomo I, del Conservador de Bienes Raíces de Nueva Imperial (Provincia de Cautín. Región de la Araucanía) Altao Coña, Graciela Ancamil, los hermanos Gallardo Quintriqueo, Dominga Quintremil y Ricardo Tranamil, participaron en las seis restantes reclamaciones pre-divisionales. Aclaradas y solucionadas las querellas, la comunidad Gallardo Tranamil fue dividida en 275 hijuelas, recibiendo en promedio 1,76 hectáreas cada adjudicatario.

Cuando la Ley fue realidad, ingresando dicha comunidad a un nuevo momento histórico, bajo recelos, desorientación y temores contenidos, sus habitantes generaron una íntima y severa evaluación al nuevo paso desplegado. La resistencia étnico-cultural del conglomerado se filtró utilizando constructos conceptuales y vivenciales, que articularon un juicio propio ante el nuevo contexto. Arturo Leiva señala al respecto, que los Mapuche entienden la existencia de las leyes "para obedecerlas; de lo contrario se es delincuente y se va a parar a la cárcel" (Leiva, 1985: 58-59).

La Ley, para los nuevos adjudicatarios, se palpó y calibró bajo la esfera de las necesidades familiares y el nivel de pobreza poseído, más las expectativas encendidas por INDAP. "Dieron la misma tierra -recuerda Sergio Tranamil-, o sea, no hubo ninguna modificación de aumento de tierra. El que tiene familiares que son hijos casados, o sea, que no le dieron, no le ampliaron mejor dicho, dejaron así no más, tal como está". A su vez, indica Isaías Ancamil:

"Había una isla por acá que estaba en común, jun retazo bien grande! ... eso 
todo el mundo metía su' anímale' nadie lo prohibía y uno tiene animales... no había ningún problema, era un terreno en común... así que ahora se dividió ese terreno... Ese fue el error, digamos, Para nosotros no fue muy positivo porque ante' como no había cerco los anímale' como quiera y ahora todo cercado, ahora todos' nos apretamos...".

En la vecina comunidad Relmul la situación no distó de la generalidad descrita. Auliel Millapi comenta: “... destructora la forma como se aplicaba la ley en el campo, por ejemplo, mapuche, Pinochet dijo: "Mire, comunidad ya no existe, 'Somos todos parcelero' y cada uno podía vender...".

Graciela Pilquiñir reclama frente al decreto ley. No se explica las razones por las cuales a los más jóvenes del sector no se les otorgaron tierras: "Eso es lo que no sabemos y ahora que a veces fallecen los papá, la mamá, quedan en sucesión no más queda la tierra; ahí pasan peleando...".

Herminia Quintremil, por su parte, sostiene en su relato: "Bueno, la división que pasó está más o menos bien, pero tampoco no se hizo bien toda la división completa, porque muchos fueron, por lo menos a nosotros, a mi madre, le han quitado varias hectáreas de tierra...".

Sabina Higuera y su marido, no recuerdan con beneplácito la materialización del decreto-ley 2.568. Si el mapuche era pobre, con la nueva Ley su situación se empeoró ostensiblemente. Acota la señora: “... esa ley por mí y mi viejo no nos gusta mucho porque ahí parece mi marido no más y no aparezco yo, y a la vez los hijos que están todos fuera". Cuestionando, consigna, la exclusión de la familia que no vive en el territorio: "No sé qué fin si después le llegaron los papeles cuanto antes y los hijos ¿dónde van a quedar? Eso es lo que sentimos un poco mal, no creo que estemos bien...".

Si bien se estipuló cronológicamente en 1981 el año en el cual los funcionarios de INDAP iniciaron sus trabajos de medición en terreno, los comuneros no nublaron sus imágenes sobre el trabajo desarrollado en sus tierras por los técnicos del Instituto Agropecuario.

La percepción que flota y permanece entre los protagonistas de la imposición estatal de división es en líneas gruesas, salvo ciertas excepciones, semejante. El trabajo desplegado por estos funcionarios fue acompañado de promesas y presiones que urgieron al mapuche, además de presentar anomalías condenables. Se referencia habitualmente, que los funcionarios en ocasiones iban al sector a trabajar y se llevaban sus "Jeep llenos de regalos". "En el caso malo conviene esto... que nos dividamos y le destinamos su retacito" -decían los funcionarios de INDAP, consigna Isaías Ancamil. Según este comunero "ese es cuco que le metían cosas a la gente. Por no perder la isla, para que el Estado no se apodere allá, entonces dijeron: "acepte la división, antes que otro se venga a meter", porque "el сисо que le metían que el Estado se hace cargo y el Estado podía destinarlo a otra persona o venderle a otro, un gringo".

La estrategia dio frutos por cuanto bajo este temor y entendiendo los comuneros en contextos dictatoriales, que ley de Estado se acata, nada podía impedir el éxito del proceso (Leiva, 1985). Si bien muchos habitantes del sector, como don Manuel Raniqueo, entendieron que los funcionarios solo cumplían con su trabajo, otros denunciaron actitudes prepotentes y deshonestas entre los personeros. “... los ingenieros no daban su buena respuesta -acota la señora Isabel Tranamil-, andaban más guapos que un león; no contestaban bien... como viene la ley, ellos mandaban".

Herminia Quintremil, endureciendo su recuerdo cataloga a dichos funcionarios como: “... medios mediocre', no eran amables; hacían las cosas como ellos querían no más y media -iqué sé yo!- 'Vamos hacer esto acá y allá' y así andaban casi retando a los mapuche...". Coincidentemente, tanto Isabel Tranamil como Herminia Quintremil, acusaron a los funcionarios de preferitismos condicionales. “... discutí con uno de ellos -señala la señorita Herminia- porque no tenía que ser asî" ya que "a veces tenían preferencia a los que le daban chanchito, cazuelita, digamos, como que se vendían de esa manera y no puede ser".

\section{Conclusión}

La situación de la reducción Gallardo Tranamil luego de ser dividida pasó por un momento de reorganización con la nueva ley indígena de 1993. El intendente de la Araucanía por aquellos años, 
Fernando Chuecas visitó el sector, alentó a la comunidad a organizarse y mirar al futuro con optimismo, porque el nuevo Gobierno democrático respetaba y valoraba a los mapuche en todo sentido, recuerda la comunidad. Los dirigentes y lonko hablaron, agradecieron a las autoridades chilenas y miraron al horizonte confiados de que la gente tendría un mejor pasar con el fin de la dictadura.

El multiculturalismo del Intendente Chuecas en territorio mapuche es expresión de un sistema semántico de dominación y control que nace, precisamente con la aplicación del decreto-ley 2.568 de 1979. A partir de esta apertura o integración de las antiguas tierras al mercado, en lógica neoliberal, la dictadura apostó por la asimilación total y definitiva de los mapuche; así, la chilenidad como expresión de identidad univoca, blanca y "civilizada", se imponía.

Las voces de hombres y mujeres de Gallardo Tranamil son ejes que permiten identificar claves discursivas, públicas y cotidianas entre sus habitantes, que dan cuenta de un proceso de reflexión que les ha permitido decantar la convulsa década de los 70 y 80 . A nivel organizacional, con este hito legislativo antimapuche, la resistencia al decreto-ley no se hizo esperar e inauguró una nueva etapa en la historia mapuche, esta vez -y pensando en Ad Mapu y su "proyecto histórico"-, signado por la lucha por autonomía y libre determinación.

A partir de esta legislación de modernización de la propiedad de la tierra, las empresas forestales tuvieron luz verde para ingresar a territorios mapuche; sabemos hoy en día que las forestales son parte constitutiva del así llamado "conflicto Estado nacional-pueblo mapuche". El Estado chileno volvió a legitimar la dicotomía decimonónica de "civilización versus barbarie".

Ahora bien, luego de cuarenta años de la entrada en vigencia de este decreto-ley, el neoliberalismo ha calado hondo en la sociedad chilena, no obstante no ha logrado asimilar a los mapuche, objetivo central de los ideólogos de esta propuesta.

\section{Agradecimiento}

Mis palabras de gratitud sea para las familias de las comunidades Gallardo Tranamil-Pichun por el apoyo constante y resuelto a mi trabajo. Especial reconocimiento a quienes ya no están con nosotros. Sin su aprecio y sabiduría, este y todos mis escritos no tendrían sentido ni razón. Mañum/Gracias.

\section{Referencias Citadas}

Ancan, J.

1994 "Los Urbanos: un nuevo sector dentro de la sociedad mapuche contemporánea", en Revista Pentakun 1. Universidad de La Frontera, Chile, pp. 21-32.

Antileo, E.

2013a "Políticas indígenas, multiculturalismo y el enfoque estatal indígena urbano". Revista de historia social y de las mentalidades 17. Universidad de Santiago de Chile. Chile, pp. 133-159.

Antileo, E.

2013b Fanon Wallmapu pule en Oliva, Elena y otros (Edit). Frantz Fanon desde América Latina: El Corregidor, Argentina, pp. 125-154.

Antileo, E et al.

2015 Awükan ka kuxankan zugu Wajmapu mew. Violencias coloniales en Wajmapu. Temuco. Ediciones Comunidad de Historia Mapuche.

Aylwin, J y Castillo, E.

1990 Legislación sobre indígenas en Chile a través de la historia. Documento de trabajo $\mathrm{N}^{\circ} 3$. Programa de Derechos Humanos y pueblos indígenas. Comisión chilena de derechos humanos. Chile.

Bastias, J.

2009 Memorias de la lucha campesina. Chile, Ediciones LOM.
Bengoa, J.

2000 Historia del pueblo Mapuche. Santiago, Ediciones Lom.

Bengoa, J.

2012 Mapuche. Procesos, políticas y culturas en el Chile del Bicentenario. Santiago, Editorial Catalonia.

Bengoa, J y Valenzuela, E.

1983 Economía Mapuche, Pobreza y subsistencia en la sociedad mapuche contemporánea. Santiago, PAS.

Cabrera Llancaqueo, J. L.

2013 Machi mongen tani Santiago warria mew. La vida de un machi en la ciudad de Santiago. Chile: Ediciones Grupo de trabajo Kuifike.

Cabrera Llancaqueo, J. L.

2016 "Complejidades conceptuales sobre el colonialismo y lo postcolonial. Aproximaciones desde el caso del Pueblo Mapuche", en Revista Izquierdas 26. Universidad de Santiago de Chile, pp. 169-191.

Canales, P.

1997 "Emergencia y tránsito de la Comunidad Gallardo Tranamil", en Revista Última Década 7. CIDPA. Viña del Mar, pp. 2-13

Canales, Pedro

1998 "Peyepeyen. Escuelas chilenas en contexto mapuche", en Revista Última Década 9. CIDAPA. Viña del Mar, pp. 2-15. 
Canales, $\mathrm{P}$

2012a "Memoria y voz mapuche en la creación de la historia. La división de la comunidad Gallardo Tranamil, 1979-1985". Revista Tiempo Histórico 5. Universidad Academia Humanismo Cristiano, pp. 129-144.

Canales, Pedro

2012b "Diputados mapuche en Chile: Debates, demandas y querellas, 1924-1973". Revista Estudios trasandinos 17. Universidad de Los Lagos, pp. 107-119.

Canales, $\mathrm{P}$

2013a. "Intelectualidad mapuche: problemáticas y desafíos", en Revista Cuicuilco 56. México. ENAH pp. 223-235.

Canales, $\mathrm{P}$.

2013b Huincul kimün. Mirando la historia «desde arriba». Revista de historia social y de las mentalidades 16. Universidad de Santiago de Chile, pp. 107-132.

Canales, $\mathrm{P}$

2014 Tierra e Historia. Estudios y controversias acerca de la historia mapuche en Chile. 1950-2010. Ediciones ULS. Chile.

Canales, P. (Edit.)

2016 Zuamgenolu. Pueblo mapuche en contexto de estado nacional chileno. Siglos XX-XX. Chile: VRIDEAEdiciones USACH.

Canio, M y Pozo, G.

2013 Historia y conocimiento oral mapuche. Sobrevivientes de la "Campaña del Desierto" y "Ocupación de la Araucanía" (1899-1926). Chile, LOM.

Caniuqueo, $\mathrm{S}$.

2006 "Siglo XX en Gulumapu: de la fragmentación del Wallmapu a la unidad nacional Mapuche. 1880-1978", en Mariman, Pablo y otros i...Escucha, winka...! Cuatro ensayos de Historia nacional Mapuche y un epilogo sobre el futuro. Chile, Ediciones LOM, pp. 129-217.

Caniuqueo, $\mathrm{S}$.

2013. "Dictadura y pueblo mapuche 1973 a 1978. Reconfiguración del 89 colonialismo chileno", en Revista de historia social y de las mentalidades 17, 1. USACH, pp. 89-130.

Carrasco, $\mathrm{H}$.

1992 Algunos fundamentos míticos del valor de la tierra entre los mapuches en Muñoz, Juan Guillermo y Orellana, Marcel (edit). Comunidades indígenas. USACH. Chile.

Correa, Martín, y otros

2004 La Reforma agraria y las tierras mapuche, $1962-$ 1975. Chile, LOM.

Correa, M y Mella, E.

2010. Las razones del Ilkün/enojo. Chile, Ediciones LOM.

Diario Austral

1979 Temuco. 31 de marzo.

Dillehay, $\mathrm{T}$.

1995 "Influencia política de los chamanes Mapuches". Revista CUHSO. Vol. II. No 2.

Foerster, R y Montecino, S.

1988 Organizaciones, líderes y contiendas mapuches. CEM.

Gaudichaud, F.

2015 Chile. Capitalismo neoliberal, trabajo y alternativas radicales. Argentina, CLACSO.
González Casanova, P.

2017 Explotación, colonialismo y lucha por la democracia en América Latina. España, Akal.

González, H.

1992 "Propiedad comunitaria o individual. Las leyes indígenas y el pueblo mapuche". Revista Nütram 3, año II, pp. 7-13.

Guevara, $\mathrm{T}$.

1913 Últimas familias mapuche. Imprenta Cervantes. Temuco.

Leiva, A.

1985 Transformaciones en la situación social de la población mapuche. Chile: CEPAL.

López Allende, R.

1990 "Efectos jurídicos de la división de la comunidad Alonso Alonqueo hacia 1988". Revista Nutram 4 Año VI.

Mallón, F.

2004 La flor del Copihue. Chile. LOM.

Mankelef, M.

1915 Las tierras mapuches. Imprenta Modernista. Temuco.

Mariman, P.

2006 "Los Mapuche antes de la conquista militar chilena argentina" en Mariman, Pablo y otros i... Escucha winka...!. Cuatro ensayos de historia mapuche y un epilogo sobre el futuro. Chile, Ediciones LOM.

Mariman, P.

2014 Trai Traiko Ni Tukulpazugun. Memoria e historia Mapuche de los territorios de Imperial. Municipalidad Nva. Imperial y Consejo Nacional de la Cultura y las Artes. Temuco.

Mariman, P.

1997 "La Diáspora Mapuche: una Reflexión Política", en Revista Liwen 4. Temuco: Centro de Estudios y Documentación Mapuche Liwen, pp. 216-223.

Mella, V.

2007 Los mapuche ante la justicia chilena. Chile. Ediciones LOM.

Menard, A.

2013. Libro diario del presidente de la Federación Araucana, Manuel Aburto Panguilef. Chile, CoLibrí.

Montecino, S.

1982 Mujeres de la Tierra. Chile, CEM-PEMCI.

Morales Urra, R.

1990 Informe de Investigación: Derechos Humanos y Opresión Étnico-Nacional. Los Mapuches en Cautín. Mimeo. Temuco.

Nahuelpan, $\mathrm{H}$.

2012 Formación colonial del Estado y desposesión en Ngulumapu en Nahuelpan, Héctor y otros. Ta iñ fijke xipa rakizuamlewün. Historia, colonialismo y resistencia desde el país Mapuche. Santiago: Ediciones Comunidad de historia Mapuche.

Pairican, F.

2014 Malón. La rebelión del movimiento mapuche. Chile: Pehuén Editores.

Pinto, J.

2015 La formación del Estado y la nación y el pueblo Mapuche. Chile: Ediciones Universidad de La Frontera.

Stuchlik, M.

1985. Las políticas indígenas en Chile y la imagen de los Mapuche. Revista CUHSO. Vol. II, No 2. UCT. Temuco. p. 54. 
Samaniego, A y Ruiz, C.

2007 Mentalidades y políticas wingka. Colección América. España.

Sentencia de división:

20-12-1985 Agregado de Propiedad. Tomo I. Conservador de Bienes Raíces. Nueva Imperial. Provincia de Cautín. Región de la Araucanía.

Vergara, $\mathrm{P}$.

1984 Auge y caída del neoliberalismo en Chile: un estudio sobre la evolución ideológica del régimen militar. Chile, FLACSO.
Vives, C.

1979 "Mapuche: pueblo amenazado", en Revista Mensaje 476. Chile.

Urrutia Leiva, M.

2019 El desalambre de los kuyfikeche. Una aproximación a las corridas de cerco en el Fundo Nehuentúe, 1971. Tesis para optar al grado de Licenciado en Historia. Universidad de Santiago de Chile. 